\title{
Integrating writing and peer learning into the optics curriculum
}

\section{Grover Swartzlander, Yvonne Merrill}

Grover A. Swartzlander Jr., Yvonne Merrill, "Integrating writing and peer learning into the optics curriculum," Proc. SPIE 9664, Ninth International Topical Meeting on Education and Training in Optics and Photonics, 96640C (24 October 2005); doi: 10.1117/12.2207683

Event: Ninth International Topical Meeting on Education and Training in Optics and Photonics, 2005, Marseille, France 
This paper is freely available as a resource for the optics and photonics education community.

\title{
Ref ETOP027
}

Integrating Writing and Peer Learning into the Optics Curriculum

\author{
Grover A. Swartzlander, Jr. and Yvonne Merrill
}

\begin{abstract}
Writing-to-learn principles and peer-learning were integrated into a third-year physical optics course for undergraduate students. By writing about the life and research of optics faculty, student benefits extended beyond the course material. Peer tutors recruited from the class helped enhanced the overall writing quality. Students published their papers on the openaccess web.
\end{abstract}

\section{Summary}

Advanced physics-based courses require problem-solving skills that may include calculus, complex numbers, trigonometry, algebra, and graphical representations. Abstract concepts are often introduced to explain familiar phenomena without a bridge to experiential knowledge. This leads to confusion and the "unlearning" of material. This abandonment of knowledge may be attributed to course content lacking qualitative information. Academic institutions pack the syllabus with technical topics, leaving little class time for integrating analytical and qualitative knowledge. Many believe students would be better prepared to master their discipline if they had experience assimilating both types of information [1,2].

Given limitations of the syllabus and class time, one approach to this problem is to require students to explore qualitative knowledge on their own time, outside of class. This approach has been used in the physics classes of one of the authors [3] - and most recently in a third year course on Physical Optics. The central focus of the assignment is a term paper. This writing assignment allows the introduction of different pedagogical techniques during the semester, e.g., writing-to-learn principles (including both formal and informal writing), peer learning methods (including peer mentoring and teamwork), communication (written and verbal), and information literacy (finding and discriminating sources).

This past year the theme of the writing project focused on both the life and research of professors engaged in physical optics activities at the University of Arizona. Students collected scientific papers, reference materials, and they interviewed their subjects. The targeted reader of each report is a first-year physics student. By spanning both personal and the scientific domains the processes needed to complete the assignment allowed the students to erect bridges between qualitative and analytical knowledge. The reports are published on the world wide web [4].

\section{References}

1. Kranber, M. "Educating the Whole Engineer." ASEE Prism. (November 1993): 28. 2. Engineering Accreditation Commission, "Criteria for Accrediting Engineering Programs (Effective for Evaluations During the 2003-2004 Accreditation Cycle)", Posted online: http://www.abet.org. (02/04/2003). 3. G. A. Swartzlander, Jr. and L. Lebduska, "Interactive Freshman Electromagnetism," ASEE/IEEE Frontiers in Education Conference Proceedings, Paper 1313, IEEE Catalog No. 02CH37351C, ISBN: 0-7803-7445-2. 4. See www.u.arizona.edu/ grovers/opti310/studenturls.html 